Pacific Journal of Mathematics

AN ELEMENTARY PROOF THAT HAAR MEASURABLE
ALMOST PERIODIC FUNCTIONS ARE CONTINUOUS 


\title{
AN ELEMENTARY PROOF THAT HAAR MEASURABLE ALMOST PERIODIC FUNCTIONS ARE CONTINUOUS
}

\author{
HENRY W. DAVIS
}

It is known that a Haar measurable complex-valued (von Neumann) almost periodic function on a locally compact $T_{0}$ topological group is continuous. For by applying the Bohr-von Neumann approximation theorem for almost periodic functions and the fact that a Haar measurable representation into the general linear group is necessarily continuous one may deduce that such a function is the uniform limit of a sequence of continuous functions. This approach, while straightforward, has the disadvantage of depending on the very deep Bohrvon Neumann approximation theorem. The latter result is commonly proven through considerable usage of representation theory. This paper presents an alternative proof that Haar measurability plus almost periodicity imply continuity. The proof is elementary in the sense that it uses only the basic definitions of almost periodic function theory and topology. It does, however, depend on the standard tools of measure theory.

Suppose $G$ is a locally compact $T_{0}$-topological group (=LC group). Let $\Gamma$ denote the set of Borel subsets of $G$, that is, the $\sigma$-algebra generated by the closed subsets of $G$. Let $\mu$ be a left Haar measure defined on $\Gamma$ (cf. [2], pp. 184-215) and let $\bar{\Gamma}$ be the completion of $\Gamma$, that is, $\bar{\Gamma}=\left\{B \cup N: B \in \Gamma, N \subset N^{\prime}\right.$, where $N^{\prime} \in \Gamma$ and $\left.\mu N^{\prime}=0\right\}$. We extend $\mu$ to the $\sigma$-algebra $\bar{\Gamma}$ by defining $\mu(B \cup N)=\mu(B)$ for all $B \cup N \in \bar{\Gamma}$. $\mu$, so extended, is left-invariant and regular on $\bar{\Gamma}$. By a $\bar{\Gamma}$-measurable function on $G$ we mean a function $f$ from $G$ to the complex plane $C$ such that $f^{-1}(A) \in \bar{\Gamma}$ for all Borel sets $A \subset C$. We are concerned with $\bar{\Gamma}$-measurable, rather $\Gamma$-measurable, functions so that in the real case, for example, we can deduce that Lebesgue measurable, as well as Borel measurable, almost periodic functions are continuous.

A set $A \subset G$ is called bounded if $\bar{A}$ is compact. We shall let $e$ denote the identity of $G$ and $\Omega$ the set of all bounded open neighborhoods of $e$ in $G$. It is convenient to use the following "density theorem" whose proof is an exercise in Halmos' Measure Theory ([1], 61.5; Halmos' "Borel" sets are different from ours but his suggested proof works equally well in our setting.).

Theorem. Let $G$ be an LC group. For any $U \in \Omega, x \in G$ and 
any bounded $E \in \bar{\Gamma}$ define

$$
d(U, E, x)=\frac{\mu\{E \cap(U x)\}}{\mu(U x)} .
$$

then $d(U, E$,$) converges in mean to the characteristic function \chi_{E}$ as $U \rightarrow e$; that is, for any $\varepsilon>0$ there is some $V \in \Omega$ such that for all $U \in \Omega, U \subset V, \int\left|d(U, E, x)-\chi_{E}(x)\right| d \mu(x)<\varepsilon$. In particular, $d(U, E$, converges in measure to $\chi_{E}$ as $U \rightarrow e, U \in \Omega$.

Lemma. Let $G$ be an $L C$ group and $f$ a $\bar{\Gamma}$-measurable almost periodic function on $G$. For any $x_{0} \in G$ and any $\delta>0$ define

$$
T\left(f, \delta, x_{0}\right)=\left\{x \in G:\left|f(x)-f\left(x_{0}\right)\right| \geqq \delta\right\} .
$$

Then

$$
\lim _{\substack{W \rightarrow e \\ U \in ?}} \frac{\mu\left\{T\left(f, \delta, x_{0}\right) \cap U x_{0}\right\}}{\mu\left(U x_{0}\right)}=0 ;
$$

that is, for any $\varepsilon>0$ there is a $V \in \Omega$ such that for all $U \in \Omega, U \subset V$,

$$
\frac{\mu\left\{T\left(f, \delta, x_{0}\right) \cap U x_{0}\right\}}{\mu\left(U x_{0}\right)}<\varepsilon .
$$

If, for example, $G$ is the additive group of real numbers, then the lemma states that a Lebesgue measurable almost periodic function is approximately continuous.

Proof of the lemma. We first show that it suffices to prove the lemma for the case $x_{0}=e$. If $x_{0} \in G$, define $f_{x_{0}}(x)=f\left(x x_{0}\right)$. Then for arbitrary $x_{0} \in G f_{x_{0}}$ satisfies the same hypotheses as $f$ (it is $\bar{\Gamma}$ measurable because right translation of the power set of $G$ by $x_{0}^{-1}$ preserves $\Gamma$ and also preserves the property of being $\mu$-null in $\Gamma$ ). Also

$$
T\left(f_{x_{0}}, \delta, e\right)=T\left(f, \hat{o}, x_{0}\right) x_{0}^{-1}
$$

so

$$
\begin{aligned}
\frac{\mu\left\{T\left(f_{x_{0}}, \delta, e\right) \cap U\right\}}{\mu(U)} & =\frac{\mu\left\{T\left(f, \delta, x_{0}\right) x_{0}^{-1} \cap U\right\}}{\mu(U)} \\
& =\frac{\mu\left\{T\left(f, \delta, x_{0}\right) \cap U x_{0}\right\}}{\mu\left(U x_{0}\right)}
\end{aligned}
$$

Thus if the lemma is true for any $\bar{\Gamma}$-measurable almost periodic function when $x_{0}=e$, then it is also true for arbitrary $x_{0} \in G$. 
We now suppose $x_{0}=e$. Take $\delta>0$. If the statement of the lemma is false, then there is a real number $\varepsilon, 0<\varepsilon<1$, such that for every $V \in \Omega$ there exists $U \subset V, U \in \Omega$, satisfying

$$
\frac{\mu\{T(f, \delta, e) \cap U\}}{\mu(U)}>\varepsilon .
$$

Take $V^{*} \in \Omega$ and define $T=T(f, \delta, e) \cap V^{*}$, so that $T$ is a bounded member of $\bar{\Gamma}$. Using the notation of the density theorem, it is the case that for every $V \in \Omega$ there is a $U \in \Omega, U \subset V$, such that $d(U, T, e)>\varepsilon$ (Take $U \subset V \cap V^{*}$ ). In what follows we make frequent use of the last statement in the density theorem.

Now $\mu(T)=t>0$ and the family $\Phi=\{V \in \Omega: d(V, T, e)>\varepsilon\}$ is a base at $e$. By the density theorem there exists $V_{0} \in \Phi$ such that

$$
\mu\left(\left\{x \in G:\left|d\left(V_{0}, T, x\right)-\chi_{T}(x)\right| \geqq \varepsilon / 2\right\}\right)<t / 2 .
$$

Thus

$$
T \not \subset\left\{x \in G:\left|d\left(V_{0}, T, x\right)-\chi_{T}(x)\right| \geqq \varepsilon / 2\right\} \text {. }
$$

Take

$$
a_{1} \in T-\left\{x \in G:\left|d\left(V_{0}, T, x\right)-\chi_{T}(x)\right| \geqq \varepsilon / 2\right\} .
$$

Then

$$
1 \geqq \frac{\mu\left(T \cap V_{0} a_{1}\right)}{\mu\left(V_{0} a_{1}\right)}=\frac{\mu\left(T a_{1}^{-1} \cap V_{0}\right)}{\mu\left(V_{0}\right)}>1-\varepsilon / 2 .
$$

Since $V_{0} \in \Phi$ we have

$$
\mu\left(V_{0}\right) \geqq \mu\left(T \cap V_{0}\right)>\mu\left(V_{0}\right) \varepsilon
$$

and

$$
\mu\left(V_{0}\right) \geqq \mu\left(T a_{1}^{-1} \cap V_{0}\right)>\mu\left(V_{0}\right)(1-\varepsilon / 2) .
$$

Consequently $\mu\left(T \cap T a_{1}^{-1}\right)>0$ so $([1], 60.5) \mu\left(T \cap T a_{1}\right)=t_{1}>0$. As $\Phi$ is a base at $e$, there exists $V_{1} \in \Phi$ such that

$$
\mu\left(\left\{x \in G:\left|d\left(V_{1}, T \cap T a_{1}, x\right)-\chi_{T \cap T a_{1}}(x)\right| \geqq \varepsilon / 2\right\}\right)<t_{1} / 2 .
$$

Therefore,

$$
T \cap T a_{1} \not \subset\left\{x \in G:\left|d\left(V_{1}, T \cap T a_{1}, x\right)-\chi_{T \cap T a_{1}}(x)\right| \geqq \varepsilon / 2\right\} .
$$

Take

$$
a_{2} \in T \cap T a_{1}-\left\{x \in G:\left|d\left(V_{1}, T \cap T a_{1}, x\right)-\chi_{T \cap T a_{1}}(x)\right| \geqq \varepsilon / 2\right\}
$$

so that $\alpha_{2} \alpha_{1}^{-1} \in T$ and 


$$
1 \geqq \frac{\mu\left(T \cap T a_{1} \cap V_{1} a_{2}\right)}{\mu\left(V_{1} a_{2}\right)}=\frac{\mu\left(T a_{2}^{-1} \cap T a_{1} a_{2}^{-1} \cap V_{1}\right)}{\mu\left(V_{1}\right)}>1-\varepsilon / 2,
$$

where $V_{1} \in \Phi$. Thus we have the following situation:

(i) $a_{1}, a_{2} \in G, a_{2} a_{1}^{-1} \in T$.

(ii) $1 \geqq \frac{\mu\left(T a_{2}^{-1} \cap T a_{1} a_{2}^{-1} \cap V\right)}{\mu(V)}>1-\varepsilon / 2$ for some $V \in \Phi$.

We shall construct by induction a sequence $\left\{a_{i}\right\}_{i=1}^{\infty} \subset G$ such that $a_{i} a_{j}^{-1} \in T$ whenever $1 \leqq j<i$. Suppose we are given

(i) $\quad a_{1}, a_{-}, \cdots, a_{m-1} \in G ; a_{i} a_{j}^{-1} \in T$ whenever $1 \leqq j<i \leqq m-1$.

(ii) $^{\prime} \quad 1 \geqq \frac{\mu\left(T a_{m-1}^{-1} \cap T a_{1} a_{m-1}^{-1} \cap \cdots \cap T a_{m-2} a_{m-1}^{-1} \cap V\right)}{\mu(V)}>1-\varepsilon / 2$

for some $V \in \Phi$. Now as $V \in \Phi$ we have

$$
\mu(V) \geqq \mu(T \cap V)>\mu(V) \varepsilon
$$

and

$$
\mu(V) \geqq \mu\left(T a_{m-1}^{-1} \cap \cdots \cap T a_{m-2} a_{m-1}^{-1} \cap V\right) \geqq \mu(V)(1-\varepsilon / 2) .
$$

Thus

$$
\mu\left(T \cap T a_{m-1}^{-1} \cap T a_{1} a_{m-1}^{-1} \cap \cdots \cap T a_{m-2} a_{m-1}^{-1}\right)>0,
$$

whence

$$
\mu\left(T \cap T a_{1} \cap \cdots \cap T a_{m-1}\right)=t^{\prime}>0 .
$$

As $\Phi$ is a base at $e$ there exists $V^{\prime} \in \Phi$ such that

$\mu\left(\left\{x \in G:\left|d\left(V^{\prime}, T \cap T a_{1} \cap \cdots \cap T a_{m-1}, x\right)-\chi_{T \cap \cdots \cap T a_{m-1}}(x)\right| \geqq \varepsilon / 2\right\}\right)<t^{\prime} / 2$.

Take

$a_{m} \in T \cap T a_{1} \cap \cdots \cap T a_{m-1}$

$$
-\left\{a \in G:\left|d\left(V^{\prime}, T \cap \cdots \cap T a_{m-1}, x\right)-\chi_{T^{\prime} \cap a_{1} \cap \cdots \cap T_{m-1}}(x)\right| \geqq \varepsilon / 2\right\} .
$$

Then $a_{m} a_{i}^{-1} \in T$ for all $i=1,2, \cdots, m-1$ and

$$
\begin{aligned}
1 & \geqq \frac{\mu\left(T \cap T a_{1} \cap \cdots \cap T a_{m-1} \cap V^{\prime} a_{m}\right)}{\mu\left(V^{\prime} a_{m}\right)} \\
& =\frac{\mu\left(T a_{m}^{-1} \cap T a_{1} a_{m}^{-1} \cap \cdots \cap T a_{m-1} a_{m}^{-1} \cap V^{\prime}\right)}{\mu\left(V^{\prime}\right)}>1-\varepsilon / 2,
\end{aligned}
$$

where $V^{\prime} \in \Phi$. As $a_{1}, \cdots, a_{m}$ satisfy conditions analogous to (i)' and (ii)', it follows that there exists a sequence $\left\{a_{i}\right\}_{i=1}^{\infty} \subset G$ such that $a_{i} a_{j}^{-1} \in T$ whenever $1 \leqq j<i$.

Now as $f$ is almost periodic, the sequence $\left\{f\left(a_{i} x\right)\right\}_{i=1}^{\infty}$ contains a uniformly convergent sub-sequence, say $\left\{f\left(a_{i}^{\prime} x\right)\right\}$. Then there exists 
$N>0$ such that

$$
\sup _{x \in G}\left|f\left(a_{i}^{\prime} x\right)-f\left(a_{j}^{\prime} x\right)\right|<\delta
$$

whenever $i>j \geqq N$. But

$$
\begin{aligned}
\sup _{x \in G} \mid & f\left(a_{i}^{\prime} x\right)-f\left(a_{j}^{\prime} x\right) \mid \\
& =\sup _{x \in G}\left|f\left(a_{i}^{\prime}\left(a_{j}^{\prime}\right)^{-1} x\right)-f(x)\right| \geqq\left|f\left(a_{i}^{\prime}\left(a_{j}^{\prime}\right)^{-1}\right)-f(e)\right| \geqq \delta,
\end{aligned}
$$

because $a_{i}^{\prime}\left(a_{j}^{\prime}\right)^{-1} \in T \subset T(f, \delta, e)$. Thus our assumption of the falsity of the lemma leads to a contradiction and the lemma is proven.

THeOREM. Let $G$ be an LC group. If an almost periodic function on $G$ is $\bar{\Gamma}$-measurable, then it is continuous.

Proof. The proof is indirect. Suppose that $f: G \rightarrow C$ is $\bar{\Gamma}$ measurable, almost periodic but not continuous. By translating $f$, if necessary, we may suppose $f$ is discontinuous at $e$. Then for some $\delta>0$ the set $T(f, \delta, e)=\{x \in G:|f(x)-f(e)| \geqq \delta\}$ intersects every neighborhood of $e$. Take some $V^{*} \in \Omega$ and let

$$
S=\{x \in G:|f(x)-f(e)|<\delta / 2\} \cap V^{*}
$$

so that $S$ is a bounded member of $\bar{\Gamma}$. By the previous lemma

$$
\lim _{\substack{U \rightarrow e \\ U \in \Omega}} \frac{\mu(S \cap U)}{\mu(U)}=1
$$

and, in particular, $\mu(S)=r>0$. We make frequent use of the last statement in the density theorem in the sequel. Also we let $\Delta$ denote symmetric difference.

There is some $U_{1}^{\prime} \in \Omega$ such that

$$
\mu\left(\left\{x \in G:\left|d(U, S, x)-\chi_{S}(x)\right| \geqq 1 / 100\right\}\right)<r / 2
$$

for all $U \in \Omega$ such that $U \subset U_{1}^{\prime}$. Choose $U_{1} \in \Omega, U_{1} \subset U_{1}^{\prime}$, such that

$$
\frac{\mu\left(S \cap U_{1}\right)}{\mu\left(U_{1}\right)}>\frac{99}{100} \text {. }
$$

There exists $a_{1} \in S-\left\{x \in G:\left|d\left(U_{1}, S, x\right)-\chi_{S}(\chi)\right| \geqq 1 / 100\right\}$ and $a_{1}$ satisfies

$$
\frac{\mu\left(S \cap U_{1} a_{1}\right)}{\mu\left(U_{1} a_{1}\right)}=\frac{\mu\left(S a_{1}^{-1} \cap U_{1}\right)}{\mu\left(U_{1}\right)}>\frac{99}{100} .
$$

Now $V=\left\{x \in G: \mu\left(x U_{1} \Delta U_{1}\right)<(1 / 100) \mu\left(U_{1}\right)\right\} \cap V^{*} \in \Omega$ (cf. [1], 61. A). Take $y_{1} \in V^{-1} \cap T(f, \delta, e)$ so that $y_{1}^{-1} \in V$ and $\left|f\left(y_{1}\right)-f(e)\right| \geqq \delta$. Then 


$$
\mu\left(y_{1}^{-1} U_{1} \cup U_{1}\right) \geqq \frac{99}{100} \mu\left(U_{1}\right) .
$$

Combining (3) with (1) and (2) and using the fact that $\mu$ is left invariant gives

$$
\begin{aligned}
\mu\left(S a_{1}^{-1} \cap y_{1}^{-1} U_{1}\right) & >\frac{98}{100} \mu\left(U_{1}\right)=\frac{98}{100} \mu\left(y_{1}^{-1} U_{1}\right) \\
\mu\left(S \cap y_{1}^{-1} U_{1}\right) & >\frac{98}{100} \mu\left(U_{1}\right)=\frac{98}{100} \mu\left(y_{1}^{-1} U_{1}\right) \\
\mu\left(y_{1}^{-1} S \cap y_{1}^{-1} U_{1}\right) & >\frac{99}{100} \mu\left(U_{1}\right)=\frac{99}{100} \mu\left(y_{1}^{-1} U_{1}\right) .
\end{aligned}
$$

Thus $\mu\left(S a_{1}^{-1} \cap S \cap y_{1}^{-1} S\right)>0$ whence $\mu\left(S \cap S a_{1} \cap y_{1}^{-1} S a_{1}\right)=s>0$. There exists $U_{2}^{\prime} \in \Omega$ such that

$$
\mu\left(\left\{x \in G:\left|d\left(U, S \cap S a_{1} \cap y_{1}^{-1} S a_{1}, x\right)-\chi_{S \cap S a_{1} \cap y_{1}^{-1} S a_{1}}(x)\right| \geqq \frac{1}{100}\right\}\right)<s / 2
$$

for all $U \in \Omega, U \subset U_{2}^{\prime}$. Choose $U_{2} \in \Omega$ such that $U_{2} \subset U_{2}^{\prime}$ and

Then

$$
\frac{\mu\left(S \cap U_{2}\right)}{\mu\left(U_{2}\right)}>\frac{99}{100} \text {. }
$$

$S \cap S a_{1} \cap y_{1}^{-1} S a_{1}$

$$
-\left\{x \in G:\left|d\left(U_{2}, S \cap S a_{1} \cap y_{1}^{-1} S a_{1}, x\right)-\chi_{S \cap S a_{1} \cap y_{1}^{-1} S a_{1}}(x)\right| \geqq \frac{1}{100}\right\} \neq \phi
$$

and we take $a_{2}$ belonging to this set. Then $a_{2}$ satisfies

$$
\begin{aligned}
\frac{\mu\left(S a_{2}^{-1} \cap S a_{1} a_{2}^{-1} \cap U_{2}\right)}{\mu\left(U_{2}\right)} & =\frac{\mu\left(S \cap S a_{1} \cap U_{2} a_{2}\right)}{\mu\left(U_{2} a_{2}\right)} \\
& \geqq \frac{\mu\left(S \cap S a_{1} \cap y_{1}^{-1} S a_{1} \cap U_{2} a_{2}\right)}{\mu\left(U_{2} a_{2}\right)}>\frac{99}{100} .
\end{aligned}
$$

Also $y_{1} a_{2} a_{1}^{-1} \in S$. We thus have the following situation:

(i) $a_{1}, a_{2} \in G ; y_{1} \in G ; y_{1} a_{2} a_{1}^{-1} \in S$.

(ii) $\left|f\left(y_{1}\right)-f(e)\right| \geqq \delta$ 。

(iii) There exists $U \in \Omega$ such that

$$
\frac{\mu(S \cap U)}{\mu(U)}>\frac{99}{100} \quad \text { and } \quad \frac{\mu\left(S a_{2}^{-1} \cap S a_{1} a_{2}^{-1} \cap U\right)}{\mu(U)}>\frac{99}{100} .
$$

Suppose the following situation is true for $m \geqq 2$ :

(i ) $a_{1}, a_{2}, \cdots, a_{m} \in G ; y_{1}, y_{2}, \cdots, y_{m-1} \in G$; and $y_{k-1} a_{k} a_{j}^{-1} \in S$ for all $1 \leqq j<k \leqq m$.

(ii) $\left|f\left(y_{i}\right)-f(e)\right| \geqq \delta$ for all $i=1, \cdots, m-1$. 
(iii)' There exists $U \in \Omega$ such that

$$
\frac{\mu(S \cap U)}{\mu(U)}>\frac{99}{100}
$$

and

$$
\frac{\mu\left(S a_{m}^{-1} \cap S a_{1} a_{m}^{-1} \cap \cdots \cap S a_{m-1} a_{m}^{-1} \cap U\right)}{\mu(U)}>\frac{99}{100} .
$$

We shall show how to obtain $a_{m+1}, y_{m} \in G$ such that $a_{1}, \cdots, a_{m+1}$ and $y_{1}, \cdots, y_{m}$ satisfy conditions analogous to (i)', (ii)', (iii)'.

Exactly as was done in the paragraph leading up to equation (3) we obtain a point $y_{m} \in T(f, \delta, e)$ such that

$$
\mu\left(y_{m}^{-1} U \cap U\right) \geqq \frac{99}{100} \mu(U) .
$$

Thus $\left|f\left(y_{m}\right)-f(e)\right| \geqq \delta$. Combining the above relation with the relations of (iii)' and using the left invariance of $\mu$, we get

$$
\begin{aligned}
& \mu\left(S \cap y_{m}^{-1} U\right)>\left(\frac{98}{100}\right) \mu(U)=\left(\frac{98}{100}\right) \mu\left(y_{m}^{-1} U\right) \\
& \mu\left(S a_{m}^{-1} \cap S a_{1} a_{m}^{-1} \cap \cdots \cap S a_{m-1} a_{m}^{-1} \cap y_{m}^{-1} U\right)>\left(\frac{98}{100}\right) \mu\left(y_{m}^{-1} U\right) \\
& \mu\left(y_{m}^{-1} S \cap y_{m}^{-1} U\right)>\left(\frac{99}{100}\right) \mu\left(y_{m}^{-1} U\right) \\
& \mu\left(y_{m}^{-1} S a_{m}^{-1} \cap y_{m}^{-1} S a_{1} a_{m}^{-1} \cap \cdots \cap y_{m}^{-1} S a_{m-1} a_{m}^{-1} \cap y_{m}^{-1} U\right)>\frac{99}{100} \mu\left(y_{m}^{-1} U\right) .
\end{aligned}
$$

Thus

$$
\begin{aligned}
& \mu\left(S \cap S \alpha_{m}^{-1} \cap S \alpha_{1} \alpha_{m}^{-1} \cap \cdots \cap S \alpha_{m-1} a_{m}^{-1}\right. \\
& \left.\quad \cap y_{m}^{-1} S \cap y_{m}^{-1} S a_{m}^{-1} \cap y_{m}^{-1} S \alpha_{1} \alpha_{m}^{-1} \cap \cdots \cap y_{m}^{-1} S a_{m-1} \alpha_{m}^{-1}\right)>0
\end{aligned}
$$

so, letting

$$
R=S \cap S a_{1} \cap S a_{2} \cap \cdots \cap S a_{m} \cap y_{m}^{-1} S \cap y_{m}^{-1} S a_{1} \cap \cdots \cap y_{m}^{-1} S a_{m},
$$

we have $\mu(R)=t>0$. There exists $W \in \Omega$ such that

$$
\mu\left(\left\{x \in G:\left|d(V, R, x)-\chi_{R}(x)\right| \geqq \frac{1}{100}\right\}\right)<t / 2
$$

for all $V \subset W, V \in \Omega$. Take $U^{\prime} \in \Omega, U^{\prime} \subset W$, such that

$$
\frac{\mu\left(S \cap U^{\prime}\right)}{\mu\left(U^{\prime}\right)}>\frac{99}{100} .
$$

Then there exists $a_{m+1} \in R-\left\{x \in G:\left|d\left(U^{\prime}, R, x\right)-\chi_{R}(x)\right| \geqq 1 / 100\right\}$. By 
definition of $R$ we have $y_{m} a_{m+1} a_{k}^{-1} \in S$ for all $k=1,2, \cdots, m$. Also

$$
\begin{aligned}
& \frac{\mu\left(S a_{m+1}^{-1} \cap S a_{1} a_{m+1}^{-1} \cap \cdots \cap S a_{m} a_{m+1}^{-1} \cap U^{\prime}\right)}{\mu\left(U^{\prime}\right)} \\
& =\frac{\mu\left(S \cap S a_{1} \cap \cdots \cap S a_{m} \cap U^{\prime} a_{m+1}\right)}{\mu\left(U^{\prime} a_{m+1}\right)} \geqq d\left(U^{\prime}, R, a_{m+1}\right)>\frac{99}{100} .
\end{aligned}
$$

Thus $a_{1}, \cdots, a_{m+1}$ and $y_{1}, \cdots, y_{m}$ satisfy conditions analogous to (i)', (ii)' and (iii)'. It follows by induction that there exist two sequences $\left\{a_{i}\right\}_{i=1}^{\infty},\left\{y_{i}\right\}_{i=1}^{\infty} \subset G$ such that $\left|f\left(y_{i}\right)-f(e)\right| \geqq \delta$ for all $i=1,2, \cdots$ and for any $k \geqq 2$ we have $y_{k-1} a_{k} a_{j}^{-1} \in S$ for $1 \leqq j<k$.

Now as $f$ is almost periodic, the sequence $\left\{f\left(x a_{m}^{-1}\right)\right\}_{m=1}^{\infty}$ contains a uniformly convergent subsequence, say $\left\{f\left(x a_{m_{k}}^{-1}\right)_{k=1}^{\infty}\right.$. Then there exists $N>0$ such that

$$
\sup _{x \in G}\left|f\left(x a_{m_{k_{1}}}^{-1}\right)-f\left(x a_{m_{k_{2}}}^{-1}\right)\right|<\delta / 2
$$

whenever $k_{1}>k_{2} \geqq N$. But

$$
\begin{aligned}
\sup _{x \in G} \mid & f\left(x a_{m_{k_{1}}}^{-1}\right)-f\left(x a_{m_{k_{2}}}^{-1}\right) \mid \\
& =\sup _{x \in G}\left|f(x)-f\left(x a_{m_{k_{1}}} a_{m_{k_{2}}}^{-1}\right)\right| \geqq\left|f\left(y_{m_{k_{1}}-1}\right)-f\left(y_{m_{k_{1}-1}{ }^{-1}} a_{m_{k_{1}}} a_{m_{k_{2}}}^{-1}\right)\right| \\
& =\left|\left\{f\left(y_{m_{k_{1}}-1}\right)-f(e)\right\}+\left\{f(e)-f\left(y_{m_{k_{1}-1}} a_{m_{k_{1}}} a_{m_{k_{2}}}^{-1}\right)\right\}\right| \\
& \geqq|| f\left(y_{m_{k_{1}}-1}\right)-f(e)|-| f(e)-f\left(y_{m_{k_{1}-1}-1} a_{m_{k_{1}}} a_{m_{k_{2}}}^{-1}\right)|| \\
& >\delta-\delta / 2=\delta / 2
\end{aligned}
$$

because each $y_{i} \in T(f, \delta, e)$ and $y_{m_{k_{1}}-1} a_{m_{k_{1}}} a_{m_{k_{2}}}^{-1} \in S$. This contradiction assures that $f$ is continuous if it is $\bar{\Gamma}$-measurable and almost periodic. The proof is completed.

\section{REFERENCES}

1. Paul R. Halmos, Measure Theory, New York, New York, 1950.

2. Edwin Hewitt, and Kenneth A. Ross, Abstract Harmonic Analysis, New York, New York, 1963.

Received November 10,1965 . This work was done while the author had a NASA predoctoral training grant and is part of a doctoral thesis written under Professor Gary H. Meisters at the University of Colorado. Preparation of the paper was supported by the project Special Research in Numerical Analysis for the Army Research Office, Durham, Contract Number DA-31-124-AROD-13, at Duke University. 


\section{PACIFIC JOURNAL OF MATHEMATICS}

\section{EDITORS}

H. SAMELSON

Stanford University

Stanford, California

J. P. JANS

University of Washington

Seattle, Washington 98105

\section{J. DugunduI}

University of Southern California Los Angeles, California 90007

RICHARD ARENS

University of California

Los Angeles, California 90024

\section{ASSOCIATE EDITORS}
E. F. BECKENBACH
B. H. NEUMANN
F. WOLF
K. YoSIDA

\section{SUPPORTING INSTITUTIONS}

\author{
UNIVERSITY OF BRITISH COLUMRIA \\ CALIFORNIA INSTITUTE OF TECHNOLOGY \\ UNIVERSITY OF CALIFORNIA \\ MONTANA STATE UNIVERSITY \\ UNIVERSITY OF NEVADA \\ NEW MEXICO STATE UNIVERSITY \\ OREGON STATE UNIVERSITY \\ UNIVERSITY OF OREGON \\ OSAKA UNIVERSITY \\ UNIVERSITY OF SOUTHERN CALIFORNIA
}

\author{
STANFORD UNIVERSITY \\ UNIVERSITY OF TOKYO \\ UNIVERSITY OF UTAH \\ WASHINGTON STATE UNIVERSITY \\ UNIVERSITY OF WASHINGTON \\ AMERICAN MATHEMATICAL SOCIETY \\ CHEVRON RESEARCH CORPORATION \\ TRW SYSTEMS \\ NAVAL ORDNANCE TEST STATION
}

Mathematical papers intended for publication in the Pacific Journal of Mathematics should be typewritten (double spaced). The first paragraph or two must be capable of being used separately as a synopsis of the entire paper. It should not contain references to the bibliography. Manuscripts may be sent to any one of the four editors. All other communications to the editors should be addressed to the managing editor, Richard Arens at the University of California, Los Angeles, California 90024 .

50 reprints per author of each article are furnished free of charge; additional copies may be obtained at cost in multiples of 50 .

The Pacific Journal of Mathematics is published monthly. Effective with Volume 16 the price per volume (3 numbers) is $\$ 8.00$; single issues, $\$ 3.00$. Special price for current issues to individual faculty members of supporting institutions and to individual members of the American Mathematical Society: $\$ 4.00$ per volume; single issues $\$ 1.50$. Back numbers are available.

Subscriptions, orders for back numbers, and changes of address should be sent to Pacific Journal of Mathematics, 103 Highland Boulevard, Berkeley 8, California.

Printed at Kokusai Bunken Insatsusha (International Academic Printing Co., Ltd.), No. 6, 2-chome, Fujimi-cho, Chiyoda-ku, Tokyo, Japan.

\section{PUBLISHED BY PACIFIC JOURNAL OF MATHEMATICS, A NON-PROFIT CORPORATION}

The Supporting Institutions listed above contribute to the cost of publication of this Journal, but they are not owners or publishers and have no responsibility for its content or policies. 


\section{Pacific Journal of Mathematics}

\section{Vol. 21, No. 2 December, 1967}

Arne P. Baartz, The measure algebra of a locally compact semigroup ..... 199

Robert F. Brown, On maps with identical fixed point sets............. 215

C. Buttin, Existence of a homotopy operator for Spencer's sequence in the analytic case ..................................... 219

Henry Werner Davis, An elementary proof that Haar measurable almost periodic functions are continuous ........................ 241

Zeev Ditzian, On asymptotic estimates for kernels of convolution transforms ...................................... 249

Robert E. Edwards, Boundedness principles and Fourier theory ......... 255

John A. Hildebrant, On compact unithetic semigroups ............... 265

Marinus A. Kaashoek and David Clark Lay, On operators whose Fredholm set is the complex plane ............................ 275

Sadao Kató, Canonical domains in several complex variables ........... 279

David Clifford Kay, The ptolemaic inequality in Hilbert geometries.... . . . 293

Joseph D. E. Konhauser, Biorthogonal polynomials suggested by the Laguerre polynomials ............................. 303

Kevin Mor McCrimmon, Macdonald's theorem with inverses .......... 315

Harry Eldon Pickett, Homomorphisms and subalgebras of multialgebras .................................... 327

Richard Dennis Sinkhorn and Paul Joseph Knopp, Concerning nonnegative matrices and doubly stochastic matrices ..............

Erling Stormer, On anti-automorphisms of von Neumann algebras ...

Miyuki Yamada, Regular semi-groups whose idempotents satisfy permutation identities .......................... 